\title{
Evaluation of Controlled Ovarian Hyperstimulation Gonadotropin Stimulation and Clomiphene Citrate Stimulation Cycles in Infertile Women
}

\author{
Yasemin Odabaş, ${ }^{1}$ Bülent Kars, ${ }^{2}$ Önder Sakin, ${ }^{2}$ Engin Ersin Şimşek ${ }^{1}$
}

'Department of Family Medicine, Kartal Dr. Lütfi Kırdar Training and Research Hospital, İstanbul, Turkey ${ }^{2}$ Department of Obstetrics and Gynecology, Kartal Dr. Lütfi Kırdar

Training and Research Hospital, istanbul, Turkey

Submitted: 23.01.2018 Accepted: 25.01.2018

Correspondence: Önder Sakin Dr. Lütfi Kırdar Kartal Eğitim ve Araştırma Hastanesi Kadın Hastalıkları ve Doğum Kliniği, Kartal, İstanbul, Turkey

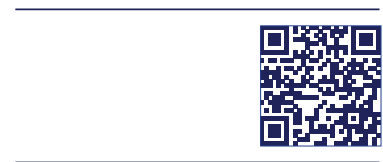

Keywords: Intrauterine insemination; pregnancy rates; unexplained infertility.

\begin{abstract}
Objective: The aim of this study was to evaluate the success of intrauterine insemination (IUI) treatment, the factors affecting success, and current recommendations.

Methods: This study was conducted by retrospectively investigating 300 cycles of IUI treatment performed in 183 patients between 2005 and 2009. The results of a single IUI treatment session performed 32 to 36 hours after a dose of 10,000 units of chorionic gonadotropin was administered to patients with unexplained infertility were analyzed. The patients were aged between 19 and 42 years with a median follicle-stimulating hormone test result of $7.15 \mathrm{mlU} / \mathrm{L}$, a total motile sperm count exceeding 5 million/mL, and a follicle size of at least $15 \mathrm{~mm}$ with treatment.
\end{abstract}

Results: The successful pregnancy rate with spontaneous coitus after clomiphene citrate (CC) treatment was $12.5 \%$ (I3/I04) The successful pregnancy rate with IUI after CC treatment was $11.7 \%(16 / 136)$, and the successful pregnancy rate with IUI after gonadotropin treatment was $23.4 \%$ (14/60). A total of $43 / 300$ pregnancies were achieved and the overall success rate was $14.3 \%$. When the results of the 43 pregnancies obtained were examined, 32 term pregnancies ( $10.7 \%)$ were achieved, there were $9(3.0 \%)$ cases of abortus, I $(0.7 \%)$ ectopic pregnancy, and I $(0.7 \%)$ chemical pregnancy.

Conclusion: CC is still the best agent for first-line treatment in couples with unexplained infertility. In cases refractory to gonadotropins, IUI promotes clinical success. IUI has the advantages of low cost, easy applicability and accessibility, low morbidity, and a significant success rate.

\section{INTRODUCTION}

Infertility is still an important issue and it is a concern for nearly 10\% of healthy couples. ${ }^{[l]}$ Important improvements have been achieved with the goal of solving infertility problems. $^{[2-5]}$ Intrauterine insemination (IUI) is first among these treatment modalities. ${ }^{[6]}$

Clomiphene citrate (CC) is one of the most frequently used drugs in IUI treatment. Worldwide, it is the most commonly used drug to stimulate ovulation. ${ }^{[7]} \mathrm{CC}$ remains the first choice agent in the treatment of infertility in pa- tients with anovulatory or normal ovulation but inadequate follicular and luteal development. In cases refractory to clomiphene citrate, gonadotropins are the most used second-line agents. ${ }^{[8,9]}$ Gonadotropins are used both in IUI and in in vitro fertilization (IVF).

The greatest advantages of IUI are its simplicity, easy applicability, low cost, and low morbidity rates. ${ }^{[2]}$ However, the rate of successful pregnancy obtained in IUI procedures performed with CC or gonadotropins differs in each clinic. Variations in application play a fundamental role in the achievement of success. 
The objective of this study was to comparatively evaluate the success rate of one clinic and to analyze the relevant factors in the light of the literature.

\section{MATERIAL AND METHODS}

In this study, 300 cycles of IUI treatment for 183 patients who registered with the infertility clinic of the hospital were retrospectively evaluated.

Patients experiencing infertility for at least I year were enrolled in the study. Baseline infertility examinations (hormone analysis, spermiograms, and gynecological examination) of the couples were performed. The patients were asked about age, gynecological and obstetric history, duration of infertility and the marriage, the presence of galactorrhea, family and personal medical history in the initial examination. Their medical history was also examined for previous abdominal surgeries, past or current presence of myoma, polycystic ovary syndrome, hyper- and hypothyroidism, hyperprolactinemia, cysts (endometriosis, ovarian, paraovarian cyst), hypogonadotropic hypogonadism, coagulation disorders (MTHFR enzymatic deficiencies), familial Mediterranean fever, and diabetes mellitus.

Hormonal analyses (thyroid-stimulating hormone, follicle-stimulating hormone $[\mathrm{FSH}]$, luteinizing hormone (LH), estradiol [E2], prolactin) and tests of fasting blood sugar and insulin were performed. Routine transvaginal ultrasound (TVUS), hysterosalpingography (HSG) and/or laparoscopy were performed. If an intrauterine lesion was detected as a result of these tests (polyp, myoma, septum, adhesion, etc.) a hysterectomy was performed, and if tubal occlusion, peritoneal adhesion, endometriosis, or adnexal mass was detected, laparoscopy was performed. If an intracavitary lesion, stage 3 or 4 endometriosis, and/or tubal adhesion were found as a result of laparoscopy and/or hysteroscopy, the patient was referred to the gynecology service for further tests and treatment. Patients with oligoanovulation, hyperprolactinemia, or hypothalamic amenorrhea were included in the ovulatory dysfunction group. Hyperprolactinemic patients were included in the study if their prolactin values returned to normal after medical treatment.

Semen analyses were performed to assess male fertility. After 3 to 5 days of abstinence, ejaculate was collected in a sterile container following masturbation, and the seminal parameters of liquefaction, warmth, volume, $\mathrm{pH}$, viscosity, sperm count and motility, and morphology were evaluated according to the World Health Organization criteria (sperm count $>20 \times 10^{6} / \mathrm{mL}$, total number of spermatozoa $>40 \times 10^{6} / \mathrm{mL}$, and forward progression $>50 \%$ ). Patients with normal or only slightly abnormal seminal parameters were included in the study. Sperm morphology and motility of less than $40 \%$ while the remainder of the seminal parameters were within normal limits was considered male factor subfertility. ${ }^{[10]}$ IUI was performed using samples of semen prepared according to the swim-up method. While preparing the semen samples for IUI, the sperm count should be at least I million/mL before the washing process.

Three treatment protocols were used: $\mathrm{CC}+$ spontaneous coitus, CC+IUI, and gonadotropins+IUI. Before initiation of CC cycles, the patients underwent an US examination, and oral CC treatment was initiated on the fifth day of menstruation at once daily doses of $50 \mathrm{mg}$, and continued for 5 days. Both spontaneous coitus and IUI cycles were monitored. After IUI, human chorionic gonadotropin (HCG) treatment was administered. TVUS-guided folliculometry was performed. If the patient had at least I follicle with a diameter of at least $22 \mathrm{~mm}$ detected during a CC cycle, she was given 10,000 IU HCG, and 32 to 36 hours later, a single session of artificial insemination was performed. Sexual intercourse on alternate days was recommended for patients on the spontaneous coitus protocol who had at least I follicle with a minimum diameter of $22 \mathrm{~mm}$.

The patients included in the gonadotropin stimulation group were evaluated based on the number of antral follicles detected with US as well as FSH and E2 values on the third day of the menstrual cycle. Individually adjusted doses of HCG were administered, and on specific days according to the response, the patients underwent a followup TVUS at intervals of at most 3 days. In the presence of at least I dominant follicle larger than $10 \mathrm{~mm}$ in size, the patient was given 1000 IU HCG and insemination was planned 34 to 36 hours later.

Measurements with TVUS were performed at the level of the corpus uteri on a longitudinal plane. The dominant follicle was defined as an ovular follicle of at least $18 \mathrm{~mm}$ in diameter in the gonadotropin cycle and $22 \mathrm{~mm}$ in the CC cycle. Clinical pregnancy was defined as a pregnancy in which a gestational sac was visualized on TVUS at 4 weeks accompanied by beta HCG values of 1000-2000 IU.

Pregnancies in which the beta HCG value was positive without the visualization of a gestational sac on TVUS were considered chemical pregnancies. Pregnant women who developed cardiac problems were monitored in the risky pregnancy polyclinic.

Statistical analyses were performed using SPSS for Windows, Version I3.0 (SPSS Inc., Chicago, IL, USA). Arithmetical means were used to evaluate the distribution pattern of variables in each group, and SD was employed to measure the dispersion of values relative to the mean. Data were expressed as mean \pm SD.

\section{RESULTS}

A total of 183 patients were retrospectively evaluated during 300 ovulation cycles. CC was administered in 240 
cycles, and gonadotropin treatment was used in 60 cycles. A total of 43 pregnancies were achieved.

The mean age of the patients was $27.41 \pm 4.85$ years (min: 19, max: 42 years). The mean length of infertility was 46.66 \pm 34.63 months (min: 9, max: 204 months). The couples had been married for a mean period of $64.88 \pm 47.87$ months (min: 12, max: 240 months). Most ( $n=137,74.8 \%)$ were instances of primary infertility, while $25.1 \%(n=46)$ were cases of secondary infertility. The mean sperm count was 67.22 \pm 49.25 million $/ \mathrm{mL}$ (min: 2.40 , max: 248.0 million $/ \mathrm{mL}$ ) and the mean sperm motility was $58.19 \%$ (min: $5.0 \%$, max: $96.6 \%)$.

The medical history of 121 (66.l\%) patients was unremarkable. There were 10 cases of polycystic ovary syndrome (5.5\%), 8 cases of hypothyroidism (4.4\%), 3 cases of ovarian cyst (I.6\%), 5 cases of hyperprolactinemia $(2.7 \%)$, and I case each $(0.5 \%)$ of hypogonadotropic hypogonadism, diabetes mellitus, and myoma. In addition, 28 patients had a history of an operation. HSG examinations revealed the presence of a uterine septum in 6 (3.3\%) patients. Radiological examinations did not disclose any evidence of a polyp (Table I).

The patients began the spontaneous coitus protocol following 104 cycles (34.7\%) of CC, and IUI was implemented after I $36(45.3 \%)$ cycles of CC or 60 (20\%) cycles of gonadotropin treatment. A total of 300 cycles of treatment were administered (Table 2). The outcome of the total of 300 cycles was pregnancy in 43 (14.3\%) cycles and no pregnancy in 257 (85.7\%) cycles (Table 3).

Successful pregnancies were seen in $13(4.3 \%)$ cycles who were included in the spontaneous coitus protocol following CC stimulation and in $16(5.3 \%)$ IUI cycles. In the gonadotropin and IUI treatment group, there were I4 (4.7\%) cycles leading to successful pregnancies. In all, 43 pregnancies were achieved, a success rate of $14.3 \%$ (Table 4 ).

Table I. Characteristics of the patients' medical histories

\begin{tabular}{lcc}
\hline Patients & $\mathbf{n}$ & $\%$ \\
\hline Unremarkable & 121 & 66.1 \\
Polycystic ovary syndrome & 10 & 5.5 \\
Surgery & 28 & 15.3 \\
Hypothyroidism & 8 & 4.4 \\
Ovarian cyst & 3 & 1.6 \\
Hyperprolactinemia & 5 & 2.7 \\
Hypogonadotropic hypogonadism & $\mathrm{I}$ & 0.5 \\
Coagulopathies & 4 & 2.2 \\
Familial Mediterranean fever & $\mathrm{I}$ & 0.5 \\
Diabetes mellitus & $\mathrm{I}$ & 0.5 \\
Myoma & $\mathrm{I}$ & 0.5 \\
Total & 183 & 100 \\
\hline
\end{tabular}

Table 2. The type and number of treatment cycles

\begin{tabular}{lcc}
\hline Treatment protocol & Number of cycles & $\%$ \\
\hline CC + Spontaneous coitus & 104 & 34.7 \\
CC + IUI & 136 & 45.3 \\
Gonadotropin + IUI & 60 & 20.0 \\
Total & 300 & 100 \\
\hline CC: Clomiphene citrate; IUI: Intrauterine insemination.
\end{tabular}

Table 3. Number of cycles and pregnancy rates

\begin{tabular}{lcc}
\hline Pregnancy & Number of cycles & $\%$ \\
\hline No & 257 & 85.7 \\
Yes & 43 & 14.3 \\
Total & 300 & 100 \\
\hline
\end{tabular}

Table 4. Pregnancy rate based on treatment modality

\begin{tabular}{lcc}
\hline Pregnancy rates & Number of cycles & $\%$ \\
\hline CC + Spontaneous coitus & 13 & 4.3 \\
CC + IUI & 16 & 5.3 \\
Gonadotropin + IUI & 14 & 4.7 \\
Total & 43 & 14.3 \\
\hline
\end{tabular}

CC: Clomiphene citrate; IUI: Intrauterine insemination.

The rates of successful pregnancy was also analyzed based on the type of treatments. CC stimulation followed by spontaneous coitus had a success rate of 13/104 (12.5\%), IUI after CC treatment yielded I6/I36 (II.7\%), and IUI after gonadotropin treatment achieved a successful pregnancy in $14 / 60(23.4 \%)$ cases.

The outcomes of the 43 pregnancies achieved were 32 term pregnancies (10.7\%), 9 miscarriages (3.0\%), I ectopic pregnancy $(0.7 \%)$, and I chemical pregnancy $(0.7 \%)$.

\section{DISCUSSION}

IUI, CC, and gonadotropin are still the subject of much discussion in the treatment of infertility. The global success rates of these procedures are a matter of interest. There are investigations indicating diverse rates of success rates and lack of any success. ${ }^{[9]}$

In research concerning IUI success rates, the potential impact of a patient's history on success, the effects of hormonal factors on fertility, the effect of primary/secondary infertility, the choice of the catheter used for IUI, the follicle diameter suitable for ovulation, the number of follicles 
required, the timing of HCG therapy, the interval after HCG treatment which is appropriate for the application of IUI, the effect of holding the cervix with a tenaculum forceps during the procedure, the decision to continue medical therapy after the procedure, the application of IUI twice within the same cycle, and sperm parameters have been frequently raised issues.

Significant increases in clinical success have been observed when all these variables were performed with the appropriate techniques, and the effects of careful attention to treatment have been demonstrated in many clinical trials. ${ }^{[10-13]}$

Each clinic has it own success rates. We evaluated the success rate in CC+spontaneous coitus, $\mathrm{CC}+\mathrm{IUI}$, and gonadotropin+lUl groups.

Sikandar et al. ${ }^{[10]}$ evaluated $290 \mathrm{IUI}$ procedures. They found a pregnancy rate per cycle of $10 \%$, a $13.8 \%$ incidence of abortus, and an $8.6 \%$ rate of ongoing pregnancy in patients aged between 20 and 44 years with unexplained infertility and follicles with a diameter of at least $16 \mathrm{~mm}$. As a result, they indicated that young individuals, those with mature follicles of a diameters over $16 \mathrm{~mm}$, and a sperm count of more than 10 million $/ \mathrm{mL}$ had a greater chance of obtaining successful results. They also stated that pregnancy rates per cycle did not demonstrate significant changes between controlled ovarian stimulation regimens. Although their pregnancy rate per cycle was slightly lower than those reported in the literature, it is noteworthy that their rate of abortus was higher than ours. However, it should not be forgotten that the risk of miscarriage ranges between $10 \%$ and $15 \%$ even in normal, spontaneous pregnancies.

Demirol et al. ${ }^{[8]}$ retrospectively investigated the records of $24 \mathrm{I}$ patients with unexplained infertility. They compared follitropin alfa $(n=8 I)$ urinary FSH $(n=80)$, and HCG $(n=80)$ groups, and determined a clinical pregnancy rate of $25.9 \%$, $13.8 \%$, and $12.5 \%$, respectively. A relatively greater number of follicles with a diameter over $16 \mathrm{~mm}$ were detected in the FSH group, and it was noted that lower drug doses were used in this group. The authors concluded that FSH provided better results. When our clinical success rate for IUI procedures per cycle using gonadotropins was assessed, gonadotropins appeared to be more effective than CC (14/60, 23.4\% vs 16/136, II.7\%).

Zafar et al. ${ }^{[1]}$ investigated 89 infertile couples. A total of 205 cycles of IUI procedures were performed in patients having follicles with a diameter ranging between 18 and $22 \mathrm{~mm}$, and 31 pregnancies were achieved. As a result of their investigation, they indicated that IUI may be a valuable procedure in young patients with a shorter duration of infertility and unexplained subfertility.

Ahinko-Hakamaa et al. ${ }^{[12]}$ retrospectively investigated I I7। cycles of CC and HCG treatments in 532 infertile couples, and estimated a pregnancy rate per cycle of $19.2 \%$, adding that the patient's age, number of follicles, the protocol applied, and the number of inseminated motile spermatozoa were significant factors.

Steures et al. ${ }^{[13]}$ performed a large-scale study in Holland analyzing the pregnancy rate achieved with IUI. They determined a pregnancy rate per cycle of $9 \%$, of which $7.3 \%$ were ongoing.

In the international literature, the pregnancy rate per cycle has been expressed as $8.7 \%$. In our clinic, 32 term pregnancies were achieved with a success rate of $10.7 \%$.

Hughes et al. ${ }^{[9]}$ investigated the efficacy of $\mathrm{CC}$ and reviewed 7 publications on randomized controlled studies. They analyzed the pregnancy outcomes of 1159 participants, and did not find that CC was superior in terms of live births when compared with untreated patients and a placebo group. (Odds ratio: $0.79,95 \%$ confidence interval: 0.45 vs $1.38 ; p=0.41$ ) No difference in clinical pregnancy rate was observed between IUI patients, and non-IUI patients, and only HCG patients. As an outcome of their investigation, they indicated that the use of CC in infertility did not confer any clinical benefit in unexplained infertility. Of course, this article contradicts the arguments of many other publications.

Yousefi et al. ${ }^{[14]}$ investigated the success rate of IUI in 26 infertile couples with an infertility history of more than 10 years. They achieved pregnancy in 7 couples (27\%) after treatment.

Chung et al. ${ }^{[15]}$ researched the pregnancy rate achieved with IUI in 340 patients, and aimed to determine the ideal stimulation protocols for an acceptable rate of pregnancy and a lower rate of multiple pregnancies. They treated 203 patients with daily doses of I50 IU FSH, and I 37 cases with $100 \mathrm{IU}$ FSH plus $100 \mathrm{mg} \mathrm{CC}$, and determined a pregnancy rate of $14.8 \%(30 / 203)$ and $20.4 \%$ (28/203), respectively. As a result, they reported that combined use of lower doses of FSH and CC not only ensured cost-effectiveness, but also prevented multiple pregnancies with a high level of satisfaction.

Almeida et al.$^{[6]}$ investigated $220 \mathrm{IUI}$ cycles in 139 couples and found a pregnancy rate per cycle of $18.6 \%$ with 5 twin pregnancies among $4 \mathrm{I}$ clinical pregnancies. The pregnancy rate with the use of $\mathrm{CC}$ was $13 \%$, with gonadotropins it was $26.1 \%$, and CC with gonadotropins yielded a rate of $28.6 \%$. A statistically significant difference in the clinical pregnancy rate was noted with the use of CC and gonadotropin. It has been also indicated that IUI is still the first-line treatment in selected infertility cases, and gonadotropins significantly increase pregnancy rates. These evaluations also coincide with our clinical success rates and conclusions.

Jasović et al. ${ }^{[2]}$ performed 97 cycles of IUI with HCG and HCG induction for 50 couples with unexplained infertility, 
and achieved 9 (18\%) singleton pregnancies. They stated that it was an effective, inexpensive, and safe treatment.

$M$ Isa et al. ${ }^{[3]}$ investigated IUI treatments in 296 women, and compared the success rates achieved with HCG and FSH. They found a significantly higher pregnancy rate was obtained with $\mathrm{FSH}, 13.28 \%$, compared with $7.14 \%$ for HCG.

Leanza et al. ${ }^{[16]}$ used $C C(n=34)$ and a multivitamin $(n=34)$ as a placebo in 68 patients with unexplained infertility. Based on IUI outcomes, they reported the development of 15 (44.1\%) pregnancies with CC and 4 (II.7\%) among the multivitamin patients. The pregnancy rates in this research are much higher than those reported in most of the literature. However, the use of CC is considerably more successful than a multivitamin placebo.

Panda et al. ${ }^{[17]}$ investigated the outcomes of IUI in 300 infertile couples and reported an IUI success rate of $17.3 \%$ in patients aged 20 to 39 years with follicles $\geq 15 \mathrm{~mm}$, an $\mathrm{LH}$ value $<10 \mathrm{mlU} / \mathrm{L}$, and an endometrial thickness $>5 \mathrm{~mm}$ on the $10^{\text {th }}$ day posttreatment with a total motile sperm count $>5$ million $/ \mathrm{mL}$

Farland et al. ${ }^{[7]}$ investigated the treatment outcomes of 10,031 patients who had undergone treatment for their infertility between the years 1993 and 2009 . They reported that $94 \%$ of the women had used CC and $73 \%$ of them had received CC stimulation therapy. Thirteen percent of these patients had received only gonadotropin injections, and $\mathrm{I} I \%$ of them were in IVF treatment. As in our clinic, $\mathrm{CC}$ is still the most frequently used infertility treatment agent in our country and worldwide.

Aanesen et al. ${ }^{[4]}$ investigated the outcomes of 380 infertile couples. In 43 patients ( I I.3\%) spontaneous pregnancy developed, while pregnancy was determined following IUI in 64 (14.5\%), controlled ovarian hyperstimulation and ovulation induction led to $16(4.2 \%)$, and II 3 (28.4\%) were observed in IVF. There were 280 pregnancies and 58 spontaneous abortions $(22.3 \%)$ in the group.

Xu et al. ${ }^{[5]}$ retrospectively investigated $5 \mathrm{I} 67 \mathrm{IUI}$ cycles in China and detected a pregnancy rate of $12.8 \%$ per cycle.

In our investigation, the outcomes of 300 treatment cycles in 183 patients were evaluated. A total of 43 pregnancies $(14.3 \%)$ were achieved after $\mathrm{CC}+$ spontaneous coitus $(n=\mid 3 ; 12.5 \%), C C+I U I(n=\mid 6 ; 11.7 \%)$, and gonadotropin therapy $(n=14 ; 23.4 \%)$.

In a comparison of general success rates, the success of IUI and of individual drug treatments, and overall or per cycle CC and gonadotropin, our results are consistent with those of the literature. We observe that IUI application techniques, application criteria, patient and drug selection, and drug protocols have not changed significantly in worldwide routine practice.

\section{Conclusion}

$\mathrm{CC}$ is still an ideal first-line treatment for couples with infertility of unknown etiology. In refractory cases, gonadotropins combined with IUI increase clinical success. The low cost, low morbidity, easy applicability, accessibility, and significant success rates of IUI procedures means that they are still a preferred initial treatment.

Ethics Committee Approval

Ethics committee approved.

Informed Consent

Retrospective study.

Peer-review

Internally peer-reviewed.

Authorship Contributions

Concept: Y.O., B.K.; Design: Y.O., B.K.; Data collection \&/ or processing: Y.O., O.S.; Analysis and/or interpretation: Y.O., B.K.; Literature search: O.S.; E.E.S.; Writing: O.S., E.E.S.; Critical review: O.S., E.E.S.

Conflict of Interest

None declared.

\section{REFERENCES}

1. Atasever M, Kalem MN, Hatırnaz Ş, Hatırnaz E, Kalem Z, Kalaylığlu Z. Factors affecting clinical pregnancy rates after IUI for the treatment of unexplained infertility and mild male subfertility. J Turk Ger Gynecol Assoc 2016;17:134-8. [CrossRef]

2. Jasović V, Jasović-Siveska E. Success rate of intrauterine insemination in patients with unknown infertility. Vojnosanit Pregl 2012;69:3017. [CrossRef]

3. M Isa A, Abu-Rafea B, Al-Asiri S, Al-Motawa J, Almady K, Alwaznah R. Ovarian stimulation medications and patients' responses as prognostic factors in IUI-treated infertile Saudi patients. Iran J Reprod Med 2014;12:493-8.

4. Aanesen A, Westerbotn M. Prospective study of a Swedish infertile cohort 2005-08: population characteristics, treatments and pregnancy rates. Fam Pract 2014;31:290-7. [CrossRef]

5. Xu YY, Wang HY, Qiao J, Liu P, Chen XN, Ma CH, et al. Analysis of clinical factors affecting pregnancy rate of intrauterine insemination. Beijing Da Xue Xue Bao Yi Xue Ban 2013;45:887-91.

6. Almeida JP, Pinelo S, Serra H, Barbosa A, Felgueira E, Pires I, et al. Controlled ovarian stimulation and intrauterine insemination: an actual therapy? Rev Bras Ginecol Obstet 2011;33:341-7.

7. Farland LV, Missmer SA, Rich-Edwards J, Chavarro JE, Barbieri RL, Grodstein F. Use of fertility treatment modalities in a large United States cohort of professional women. Fertil Steril 2014;101:170510. [CrossRef]

8. Demirol A, Gurgan T. Comparison of different gonadotrophin preparations in intrauterine insemination cycles for the treatment of unexplained infertility: a prospective, randomized study. Hum Reprod 2007;22:97-100. [CrossRef]

9. Hughes E, Brown J, Collins JJ, Vanderkerchove P. Clomiphene citrate for unexplained subfertility in women. Cochrane Database Syst Rev 


\section{0:CD000057. [CrossRef]}

10. Sikandar R, Virk S, Lakhani S, Sahab H, Rizvi J. Intrauterine insemination with controlled ovarian hyperstimulation in the treatment of subfertility. J Coll Physicians Surg Pak 2005;15:782-5.

11. Zafar M, Jameel T, Abdullah KN. Impact of intrauterine insemination as first line treatment of subfertility. J Pak Med Assoc 2007;57:133-6.

12. Ahinko-Hakamaa $\mathrm{K}$, Huhtala $\mathrm{H}$, Tinkanen $\mathrm{H}$. Success in intrauterine insemination: the role of etiology. Acta Obstet Gynecol Scand 2007;86:855-60. [CrossRef]

13. Steures P, van der Steeg JW, Hompes PG, Bossuyt PM, van der Veen F, Habbema JD, et al. Intra-uterine insemination with controlled ovarian hyperstimulation compared to an expectant management in couples with unexplained subfertility and an intermediate prognosis: a randomised study. Ned Tijdschr Geneeskd 2008;152:1525-31.

14. Yousefi B, Azargon A. Predictive factors of intrauterine insemination success of women with infertility over 10 years. J Pak Med Assoc 2011;61:165-8.

15. Chung MT, Chan TF, Loo TC, Tang HH, Lin LY, Tsai YC. Comparison of the effect of two different doses of recombinant gonadotropin for ovarian stimulation on the outcome of intrauterine insemination. Taiwan J Obstet Gynecol 2011;50:58-61. [CrossRef]

16. Leanza V, Coco L, Grasso F, Leanza G, Zarbo G, Palumbo M. Ovulation induction with clomiphene citrate for infertile couple. Minerva Ginecol 2014;66:309-12.

17. Panda B, Mohapatra L, Sahu MC, Padhy RN. Success in pregnancy through intrauterine insemination at first cycle in 300 infertile couples: an analysis. J Obstet Gynaecol India 2014;64:134-42. [CrossRef]

\section{Kontrollü Overyan Hiperstimülasyonu Uygulanan İnfertil Olgularda Klomifen Sitratlı Stimülasyon Ile Gonadotropinli Stimülasyon Sikluslarının Değerlendirilmesi}

Amaç: Amacımız günümüzde intrauterin inseminasyon (IUi) tedavisinin başarısını, başarıyı etkileyen faktörleri ve güncel önerileri incelemektir.

Gereç ve Yöntem: Bu çalışma hastanemizde 2005-2009 tarihleri arasında 183 hastanın 300 siklus tedavisi geriye dönük olarak incelenerek yapıldı. Hastalar 19-42 yaş arası, açıklanamayan infertilitesi olan, FSH değeri ortalama $7.15 \mathrm{mlU} / \mathrm{L}$ olan, total hareketli sperm sayısı 5 milyon/ $\mathrm{mL}$ üzerinde olanlarda, tedavi ile follikül boyutu $15 \mathrm{~mm}$ üzerinde olan, HCG dozu 10.000 ünite sonrası 32-36 saat sonra tek seans iUi tedavisinin başarısı ve sonuçları geriye dönük olarak incelendi.

Bulgular: Hastalara klomifen sitrat sonrası spontan koit tedavisi ile başarılı gebelik I3/I04 (\%/2.5). klomifen sitrat sonrası IUI tedavisi ile başarı gebelik I6/I36 (\%II.7), gonadotropin tedavisi sonrası IUI işlemi ile başarılı gebelik I4/60 (\%23.4) olarak belirlendi. Toplamda 43/300 gebelik sağlanmış olup başarı oranı \%।4.3 idi. Elde edilen 43 gebeliğin sonuçları incelendiğinde 32 term gebelik (\%।0.7) abortus gerçekleşen 9 (\%3.0), ektopik gebelik I (\%0.7) ve kimyasal gebelik I (\%0.7) olarak belirlendi.

Sonuç: Klomifen sitrat nedeni bilinmeyen infertil çiftlerde halen ilk basamak tedavi için ideal bir ajandır. Cevap alınamayanlarda gonadotropinler ile iUi klinik başarıyı artırmaktadır. İntrauterin inseminasyon işlemleri; düşük maliyeti, kolay uygulanabilirliği, kolay ulaşılabilirliği, düşük morbiditesi ve anlamlı başarısı ile infertil çiftlerde ilk basamak tedavide öncelikli uygulanması gereken yöntem olarak yerini korumaktadır.

Anahtar Sözcükler: Açıklanamayan infertilite; gebelik oranları; intrauterin inseminasyon. 